\title{
CORREÇÃO DO FLUXO ESCOLAR: UM BALANÇO DO PROGRAMA ACELERA BRASIL ( 1997-2000)
}

\author{
JOÃO BATISTA ARAUJO E OLIVEIRA* \\ Consultor e Presidente da JM-Associados \\ joaobatista@mit.edu; jm@zaz.com.br
}

\begin{abstract}
RESUMO
A correção do fluxo escolar consiste no desafio inicial a ser superado para que o Brasil possa oferecer educação de qualidade para todos. Dos 35,7 milhões de alunos matriculados no ensino fundamental, no início do ano 2000, quase 20 milhões estavam com dois ou mais anos de atraso escolar, e, dentre esses, 9 milhões já tinham mais de 15 anos de idade. Este artigo apresenta, descreve e analisa resultados do Programa Acelera Brasil, desenvolvido em 24 municípios durante os anos 1997 a 2000. O programa envolveu quase 60 mil alunos em mais de 2.400 classes e teve como objetivo regularizar o fluxo escolar através da implementação de programas de alfabetização, programas de aceleração de aprendizagem e outras estratégias que visam assegurar os avanços obtidos. Embora as metas iniciais do programa de aprovar os alunos para a $5^{a}$ série e regularizar o fluxo escolar num prazo de quatro anos não tenham sido plenamente atingidas, os resultados obtidos sugerem uma taxa de sucesso que varia entre $70 \%$ e $90 \%$, nos diferentes municípios. Do ponto de vista econômico, foram economizados mais de 50 milhões de reais, o que significa uma taxa de retorno superior a $300 \%$ do investimento. Os resultados obtidos permitiram a implementação maciça do programa em outros estados e municípios do país, com resultados semelhantes. O artigo conclui com uma discussão a respeito das contribuiçóes desse programa para a formulação de políticas públicas consistentes para a correção do fluxo escolar. REPETÊNNCIA - PROGRAMA ACELERA BRASIL - POLITICAS PÚBLICAS - PEDAGOGIA
\end{abstract}

* O autor, desde 1994, está envolvido com o desenvolvimento de projetos e políticas relacionados com o fluxo escolar, tendo sido idealizador e orientador, entre outros, do programa analisado neste artigo. 


\begin{abstract}
REDRESSING STUDENT FLOWS: RESULTS OF PROGRAMA ACELERA BRASIL (19972000). The paper analyses results of Programa Acelera Brasil implemented in 24 municipalities between 1997 and 2000. Over 60,000 students participated in more than 2400 classrooms. The main goal was to correct student flows through the implementation of literacy and acceleration programs for over-age students, as well as other strategies to sustain the results achieved. Even though the original targets to promote students to the $5^{\text {th }}$ grade and correct the flow within 4 years were not fully attained, the results suggest a success rate varying from $70 \%$ to $90 \%$ in the different municipalities. From an economical perspective, over 50 million reais were saved, implying a threefold rate of return. The results obtained led to the massive implementation of the strategy in other states and municipalities, with similar results. The paper ends with a discussion about the contributions of Acelera Brasil to the formulation of consistent public policies to redress student flows.

GRADE REPETITION - PUBLICS POLICIES - PEDAGOGY
\end{abstract}

O Programa Acelera Brasil - PAB - foi iniciado no ano de 1997. É uma das iniciativas que, como outras desenvolvidas no Brasil a partir de 1995, visavam corrigir o fluxo escolar em redes estaduais e municipais de ensino, como estratégia para possibilitar a implementação de um sistema de ensino fundamental de qualidade para todos.

Os primeiros esforços foram desenvolvidos no Estado do Maranhão ainda em 1995, seguidos do Programa Acelera Brasil, patrocinado pelo Instituto Ayrton Senna - IAS (Oliveira, 200 la), do Programa de Aceleração da Aprendizagem do Estado de São Paulo, voltado para as quatro primeiras séries do ensino fundamental, bem como do Programa Ensinar e Aprender, para as quatro últimas séries do ensino fundamental, implementado no Estado do Paraná a partir de 1998. Após o ano de 2000 o Estado da Bahia também passou a implementar os mesmos programas do IAS e criou um programa próprio para alunos defasados de $5^{\mathrm{a}}$ a $8^{\mathrm{a}}$ série (Oliveira, 200I).

$\mathrm{OAB}$, analisado neste artigo, embora integre esse conjunto de esforços e compartilhe objetivos e práticas comuns a outros programas, diferencia-se de outras iniciativas pelas características listadas a seguir. A mais importante delas reside no compromisso explícito com a regularização do fluxo escolar, e não simplesmente com a aceleração de alunos, que é a atitude mais comum na maioria de programas que foram desenvolvidos no país desde 1995. Trata-se, portanto, de um programa de mudança de vetor na política educacional comprometido com resultados permanentes e não com uma mera inovação ou intervenção pedagógica. 


\section{Caracterizam o PAB:}

- articulação por uma entidade não governamental, o Instituto Ayrton Senna';

- estratégia e materiais de ensino concebidos para posterior utilização em qualquer estado ou município;

- objetivo da ação: demonstrar que é viável a correção do fluxo escolar num prazo máximo de quatro anos, em grande escala, por redes de ensino funcionando nas várias circunstâncias típicas do sistema de educação pública do país;

- estratégia de implementação, que inclui:

- compromisso político das autoridades com a regularização do fluxo, e não meramente com a aceleração de estudos;

- financiamento adequado;

- estrutura gerencial local;

- materiais próprios para alunos defasados;

- materiais de apoio para a classe e para os professores;

- sistemática de acompanhamento, planejamento e controle do processo;

- sistemática de supervisão semanal a cada classe;

- reuniões quinzenais de avaliação e planejamento pelos professores;

- assistência técnica para o gerenciamento do programa;

- material estruturado para capacitação de professores em serviço (Capacitar);

- estratégias e materiais para diagnóstico e alfabetização de alunos defasados e não alfabetizados;

- avaliação externa anual, realizada pela Fundação Carlos Chagas (FCC), e

- acompanhamento dos egressos e da sustentabilidade do programa.

PAB, com essas características, foi implementado inicialmente em 15 municípios, no ano de 1997, e ampliado para 24 municípios a partir de 1998. Em

I. O Instituto Ayrton Senna utiliza o conceito de aliança estratégica para articular apoios técnicos e financeiros de outras instituições, públicas ou privadas, para implementar seus projetos. No caso do Acelera Brasil e do Acelera Goiás, os principais parceiros, em diferentes momentos, foram a Petrobrás, o Banco Nacional de Desenvolvimento Econômico e Social (BNDES), o Fundo Nacional de Desenvolvimento da Educação (FNDE)/Ministério da Educação e Cultura (MEC) e a Telefônica Centro-Oeste (TCO). 
1999 foram incluídas as redes estaduais e municipais dos estados de Goiás e Espírito Santo².

Em 200 I foi estabelecida, pelo IAS, a Rede Acelera Brasil, composta pelos municípios ex-participantes do PAB. A rede tem dois objetivos principais: assegurar a consolidação do projeto nesses municípios e promover, disseminar e disponibilizar a tecnologia de intervenção, para corrigir o fluxo escolar, a outras redes de ensino.

\section{METODOLOGIA}

O programa é implementado seguindo a mesma metodologia, tanto em redes estaduais quanto municipais. Muda apenas a estratégia de gerenciamento.

Com base na identificação e localização dos alunos defasados, é elaborado um plano para regularizar o fluxo escolar que, em princípio, deve acontecer dentro de um prazo máximo de quatro anos, no município ou estado, e de dois anos para cada escola, de maneira a não criar estigma de programa para alunos atrasados.

Uma vez identificados os alunos, é feito um teste diagnóstico para separar os defasados alfabetizados dos defasados não alfabetizados. Essa triagem tornou-se necessária pela constatação de que entre 20\% a 40\% do total de defasados das quatro primeiras séries eram analfabetos, e, portanto, necessitavam ser alfabetizados antes de ingressarem no programa, que pressupõe sejam os alunos capazes de ler e compreender o que lêem ${ }^{3}$.

Em cada município o programa é gerenciado por um coordenador municipal, a quem compete identificar as escolas, professores, supervisores e alunos que participarão do programa a cada ano.

A equipe local participa de uma breve capacitação inicial, com o objetivo específico de apresentar a sistemática operacional do programa. Durante o ano letivo os professores recebem uma visita semanal do respectivo supervisor e participam de reuniões quinzenais de avaliação, troca de experiências e planejamento

2. O Estado do Espírito Santo deixou de participar do PAB desde 200 I, mas continuou operando um programa de aceleração de aprendizagem com orientação própria.

3. A descoberta de que um elevado contingente de alunos defasados das quatro séries das escolas públicas brasileiras não é capaz de ler e escrever sequer nos níveis de decodificação e compreensão mais elementares levou o IAS a desenvolver uma estratégia para alfabetizar esses alunos, descrita adiante neste documento. $\bigcirc$ problema, no entanto, revela uma deficiência adicional do setor público, que é a falta de estratégias adequadas de alfabetização. 
das atividades junto com outros professores, assistidos pelo mesmo supervisor ${ }^{4}$. Além disso, os professores participam, com os colegas de sua escola, dos programas do curso à distância - Capacitar, cuja função estratégica no programa será discutida adiante.

Ao longo do projeto são coletadas diariamente e consolidadas mensalmente informações a respeito da freqüência de alunos e professores, abandono dos alunos, registro das visitas dos supervisores, participação dos professores nas reuniões quinzenais, andamento do ritmo do programa e número de livros lidos pelos alunos. Esses dados são analisados pelos professores, supervisores, coordenadores e pela equipe central que proporciona assistência técnica ao projeto, visando à correção de rumos.

O PAB conta com materiais didáticos estruturados para os alunos, caixas de materiais complementares para realizarem as atividades e projetos previstos nos materiais, compostos de livros de leitura (25 títulos para alunos de alfabetização e 40 títulos para alunos de aceleração), dicionários, mapas, revistas, manuais para os professores, além de manuais operacionais contendo instruções para os coordenadores, supervisores e professores. Esses materiais foram concebidos sob a orientação do autor e têm como objetivo permitir aos alunos, através de pequenas realizações, adquirir a noção de que eles são capazes de aprender e ter sucesso na escola, desde que submetidos a tratamento pedagógico adequado. Os pressupostos cognitivos do programa são descritos no livro $A$ pedagogia do sucesso (Oliveira, 200 la).

A expectativa do PAB é promover os alunos para a $5^{\mathrm{a}}$ série ou até para a $6^{\mathrm{a}}$ ou $7^{a}$ séries. No entanto, quem decide pela aprovação e número de "saltos" é o professor, ouvido o supervisor ou conselho de classe, dependendo da escola, sem qualquer interferência ou pressão do projeto.

Ao longo dos quatro anos de duração do projeto foi efetuada sua avaliação externa, por amostragem, pela Fundação Carlos Chagas. A avaliação externa inclui a realização de pré e pós testes de Português e Matemática. $\bigcirc$ teste aplicado ao final do ano assegura a comparabilidade com o Sistema Nacional de Avaliação do Ensino Básico - Saeb - da $4^{a}$ série. Os detalhes a respeito desse teste e dessas amostras estão apresentados em relatórios anuais e no relatório final da avaliação externa (FCC, 200I).

4. A hipótese mais provável sobre o ensino público brasileiro é que a maioria dos alunos que aprende a ler, nessas escolas, o faz apesar da escola, e não em virtude dela. 


\section{RESULTADOS}

Os resultados apresentados concentram-se essencialmente no PAB desenvolvido em 24 municípios de todas as regiões do país. Os dados do programa estadual em Goiás serão reportados em outro documento, tendo em vista que ainda se encontra em andamento. De modo geral, esses resultados, bem como os resultados parciais do programa implementado no Estado do Espírito Santo, corroboram os dados apresentados neste artigo. Oliveira (200 I) apresenta resultados similares do programa de Regularização do Fluxo Escolar do Estado da Bahia, que, embora não seja patrocinado pelo IAS, segue a mesma metodologia.

\section{PERFIL DOS ALUNOS}

Define-se como defasado o aluno com 2 ou mais anos de distorção em relação à série em que deveria estar. $\bigcirc$ perfil dos alunos do Programa foi se modificando ao longo do tempo - nos primeiros anos participaram os alunos mais velhos e com maior número de repetências. Os dados coletados com os alunos que participaram do programa no ano de 2000 revelam o perfil (FCC, 200 I) mostrado no quadro I.

Cabe observar que nem todos os alunos defasados eram repetentes ou multirrepetentes, em particular nas turmas atendidas no ano 2000. Uma pequena parte da defasagem deve-se à entrada tardia ou ao abandono, que é uma espécie de repetência branca: o aluno sai da escola para não ser reprovado e retorna no ano seguinte.

\section{COBERTURA}

Em 1997, os municípios participantes possuíam níveis de defasagem típicos das suas regiões. No Brasil, esse índice situava-se entre 50 e $70 \%$ na maioria dos municípios.

A tabela I apresenta o número de alunos atendidos pelo programa nos 24 municípios, entre 1997 e 200 I, nas classes de Aceleração e de Alfabetização.

O programa de alfabetização só foi patrocinado pelo Instituto Ayrton Senna no ano de 1999, nos anos subseqüentes os municípios desenvolveram esse programa por conta própria, daí a inexistência de dados sistematizados.

A tabela 2 apresenta os dados disponíveis, referentes a 6 dos municípios integrantes do programa. 
QUADRO I

PERFIL DOS ALUNOS DO PAB- PROGRAMA ACELERA BRASIL

\begin{tabular}{|c|c|}
\hline Sexo & A- $55,8 \%$ Masculino \\
\hline Idade & $\begin{array}{l}\text { B- } 35 \% \text { com menos de } 10 \text { anos } \\
\text { C- } 59,7 \% \text { entre } 11 \text { e } 14 \text { anos } \\
\text { D- } 5,2 \% \text { com mais de } 15 \text { anos }\end{array}$ \\
\hline Série de origem & $\begin{array}{l}\text { E- } 1^{2}-14,3 \% \\
\text { F- } 2^{2}-40,6 \% \\
\text { G- } 3^{2}-41,8 \% \\
\text { H- } 4^{2}-3,2 \%\end{array}$ \\
\hline Zona & I- $70,8 \%$ urbana \\
\hline Familia & $\begin{array}{l}\text { J- } \quad 67,2 \% \text { mora com pais e irmãos } \\
\text { K- } 4 \% \text { mora só com pai e mãe } \\
\text { L- } 15,2 \% \text { mora só com mãe } \\
\text { M- } 3,9 \% \text { mora só com pai } \\
\text { N- } 9,6 \% \text { mora com outras pessoas }\end{array}$ \\
\hline Escolaridade dos pais ou responsável & $\begin{array}{l}\text { O- } 17 \% \text { nunca freqüentou escola } \\
\text { P- } 34,6 \% \text { freqüentou alguns anos } \\
\text { Q- } 21,6 \% \text { freqüentou até } 44^{\circ} \text { série } \\
\text { R- } 12,1 \% \text { freqüentou até } 8^{\circ} \text { série }\end{array}$ \\
\hline Trabalho dos pais & $\begin{array}{l}\text { S- } 76,9 \% \text { dos pais trabalham } \\
\text { T- } 46,3 \% \text { das mães trabalham } \\
\text { U- } 15,3 \% \text { dos pais são aposentados } \\
\text { V- } 9,6 \% \text { das mães são aposentadas } \\
\text { W- } 7,7 \text { dos pais não trabalham ( } 44 \% \text { das mães) }\end{array}$ \\
\hline $\begin{array}{l}\text { Idade com que alunos começaram a } \\
\text { trabalhar }\end{array}$ & $\begin{array}{l}\text { X- } 78,3 \% \text { não trabalham } \\
\text { Y- } 18,9 \% \text { trabalham desde antes de } 14 \text { anos } \\
\text { Z- } 2,8 \% \text { começar am depois de } 14 \text { anos }\end{array}$ \\
\hline $\begin{array}{l}\text { Idade com que alunos começaram a } \\
\text { freqüentar a escola }\end{array}$ & $\begin{array}{l}\text { AA- } 77,2 \% \text { antes dos } 8 \text { anos } \\
\text { BB- } 15,9 \% \text { entre } 9 \text { e } 10 \text { anos } \\
\text { CC- } 6,9 \% \text { com mais de } 10 \text { anos }\end{array}$ \\
\hline Número de repetências & $\begin{array}{l}\text { DD-zero: } 28,3 \% \\
\text { EE- uma: } 31,7 \% \\
\text { FF- duas: } 27 \% \\
\text { GG-3 oumais: } 13 \%\end{array}$ \\
\hline
\end{tabular}


TABELA I

ATENDIMENTO DO PROGRAMA ACELERA BRASIL

\begin{tabular}{lrrrrr} 
& 1997 & 1998 & 1999 & 2000 & Total \\
\hline Alfabetização & & & 6.918 & & 6.918 \\
Aceleração & 3.119 & 20.746 & 18.665 & 8.810 & 51.340 \\
Total & & & & & 58.258 \\
\hline
\end{tabular}

Fonte: IAS/PAB, 200I.

A tabela 2 apresenta três informações que merecem destaque. Primeiro, em alguns municípios com pouco influxo de novos alunos, como Pereiro, Rio Branco e Sapiranga, o projeto contribuiu para reduzir o total de matrículas no ensino fundamental - antes inflacionado pela elevada presença de defasados. Segundo, em alguns municípios como Sobral e São Vicente, apesar do influxo de novos alunos ter aumentado significativamente o tamanho da rede municipal, houve sensível redução na proporção de defasados. Terceiro, apesar dos esforços dos municípios, os índices de defasagem ainda permanecem relativamente elevados. Ao final do ano 2000, do total de 24 municípios envolvidos no programa, 10 estavam com níveis inferiores a 10\% de defasagem, e a média geral era de 22\%, que deve ser comparada com a média nacional, superior a 40\%.

No ano de 200 I os municípios envolvidos no projeto continuaram os esforços para corrigir o fluxo escolar e passaram a adotar novas práticas de acompanhamento e controle do fluxo escolar nas escolas, para assegurar que o fenômeno não volte a se repetir. Essas medidas práticas incluem o acompanhamento sistemático de freqüência dos alunos, adoção de instrumentos de diagnóstico para novos alunos e critérios para enturmação, políticas de alfabetização de alunos novos e defasados, além de avaliação externa. Esses esforços continuam a ser articulados pelo Instituto Ayrton Senna, sob o nome de Rede Acelera.

\section{DESEMPENHO DOS ALUNOS}

\section{Taxas de abandono}

As taxas anuais de abandono do programa são de 9\% nos anos de 1998, 1999 e 2000, respectivamente. Taxas de abandono são calculadas como a diferença entre alunos inscritos no programa no início do ano e alunos que não se encon- 
总总覀

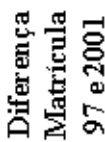

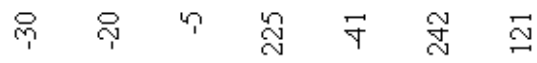

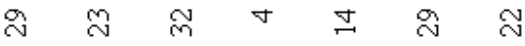

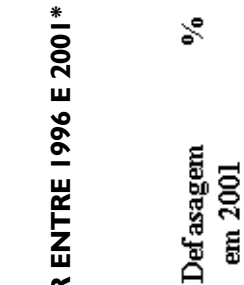

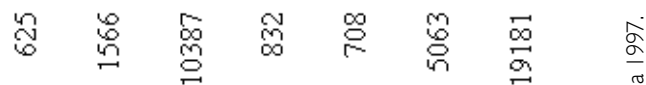

象

苞兽

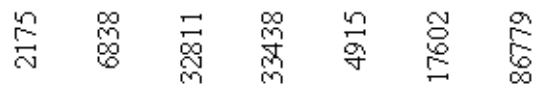

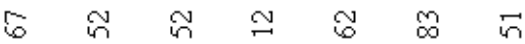

웅

安

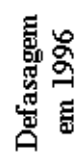

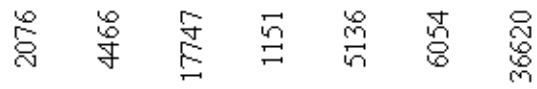

密

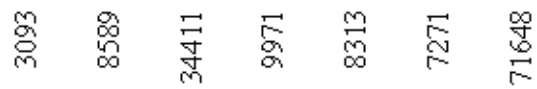

量

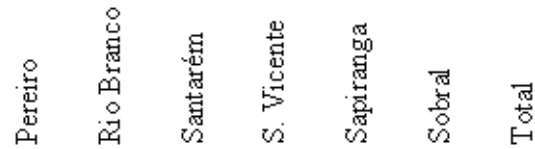


travam no programa ao final do ano. Essas taxas são significativamente inferiores às taxas de abandono reportadas nos relatórios do Censo Escolar do MEC/Inep até o ano 2000.

As taxas de abandono dos alunos do PAB são 50\% menores do que as taxas de abandono dos demais alunos das mesmas escolas. Quanto às causas do abandono, levantamento realizado no ano de 1998 com os alunos revela que $50 \%$ do abandono se devem a fatores extra-escolares (economia familiar, migração, doença) e a outra metade, a problemas que poderiam ser evitados com cuidados extras de escolas e professores 5 .

\section{Taxas de aprovação e de "aceleração"}

A tabela 3 apresenta as taxas de aprovação e aceleração dos alunos, ao longo dos quatro anos do projeto. Um salto médio de I,7 significa que os alunos passaram de ano e ainda cumpriram 0,7 da série seguinte, perfazendo 7 séries completadas num ano letivo. Portanto, o total de 51.340 alunos corresponde a 87.278 séries letivas aprovadas, uma vez que alguns alunos foram acelerados, ou seja, concluíram mais do que uma série escolar como resultado de sua participação no PAB.

TABELA 3

TAXAS DE APROVAÇÃO E ACELERAÇÃO $1997-2000$

\begin{tabular}{|c|c|c|c|}
\hline Ano & Salto & \% Promoção & \% Retenção \\
\hline 97 & 1.8 & 99 & 1 \\
\hline 98 & 1.8 & 95 & 5 \\
\hline 99 & 1.6 & 95 & 5 \\
\hline 2000 & 1.7 & 95 & 5 \\
\hline
\end{tabular}

Fonte: IAS/PAB, 200|

5. O Centro de Ensino Tecnológico de Brasília - Ceteb - participou das primeiras iniciativas de aceleração no Estado do Maranhão em 1995, sob a orientação do autor deste artigo, e atuou como agente técnico do Instituto Ayrton Senna no período de 1997 a 2000. Os dados mencionados constam de relatórios internos do Ceteb apresentados ao Instituto Ayrton Senna no decorrer do programa. Conforme registrado nos manuais do programa e no livro $A$ pedagogia do sucesso, a freqüência do aluno é um dos temas estratégicos do programa, e na sua implementação os professores e comunidades são envolvidos de forma que minimizem os problemas de absenteísmo e abandono. Além do problema dos alunos defasados não alfabetizados, fatores extra-programa, sobretudo calendários escolares inadequados, explicam parte importante das elevadas taxas de abandono que ainda se verificam. 
Cabe observar que apesar das orientações e recomendações do programa referentes a atividades de recuperação paralela, ainda existe uma taxa residual de reprovação, muitas vezes devida a equívocos na seleção de alunos (analfabetos, alunos provenientes de programas de educação especial, alunos com elevado nível de ausências). Por outro lado, esses dados comprovam tanto o arraigamento da pedagogia da repetência quanto o fato de que o programa não impõe obrigatoriedade de promoção automática, respeitando a autonomia do professor e da escola.

Os índices de aprovação são superiores a 95\% para alunos que, em sua expressiva maioria, tiveram uma longa história de reprovações. As taxas de aceleração revelam que os alunos defasados não apenas passaram de ano, mas foram autorizados a "acelerar", pulando séries. A série de destino está fortemente associada à série de origem - a maioria dos alunos que vai para a $5^{\mathrm{a}}$ série ou mais provém da $3^{\mathrm{a}}$ série. Alunos que fizeram apenas o programa de alfabetização também foram autorizados a saltar séries por seu professor, na proporção de I,3 saltos por aluno em média.

O quadro 2 apresenta a distribuição dos alunos segundo a série para a qual eles foram promovidos ao longo do projeto.

\section{QUADRO 2 \\ DISTRIBUIÇÃO DOS ALUNOS SEGUNDO A SÉRIE PARA A QUAL FORAM PROMOVIDOS NOS ANOS DE 1997, 1998, 1999 E 2000}

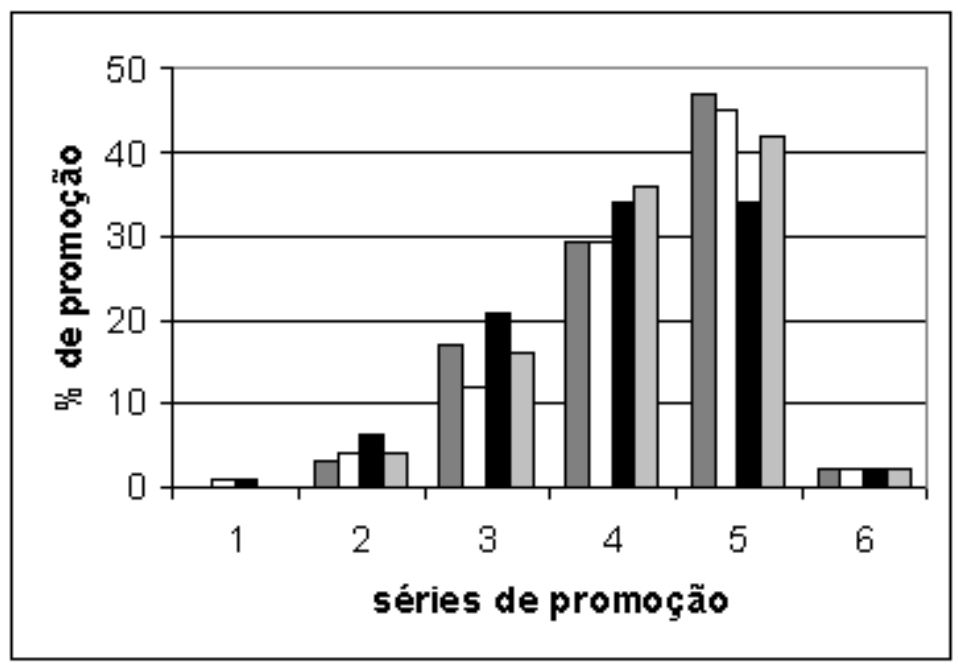

Fonte: FCC, 2001 


\section{Desempenho dos egressos}

A cada ano são coletados dados dos egressos do programa numa amostra de escolas dos municípios. Os dados coletados em 2000, referentes aos egressos do $\mathrm{PAB}$, nas séries $3^{\mathrm{a}}, 4^{\mathrm{a}}, 5^{\mathrm{a}}$ e $6^{\mathrm{a}}$, apresentados nos quadros 3 a 7 , mostram que esses alunos apresentaram um desempenho sempre inferior, mas muito próximo à média geral das turmas que freqüentam.

O quadro 7 sintetiza as porcentagens de aprovação, reprovação, transferência e evasão dos alunos egressos do PAB de 1997, 1998 e 1999 em 2000, com relação aos alunos do ensino regular. Esse quadro revela índice de aprovação inferior, e uma associação negativa entre abandono e reprovação: maior a evasão, menor a reprovação. Ainda assim, há uma diferença acentuada entre a porcentagem de reprovação dos alunos regulares (9\%), a dos alunos e a dos ex-alunos do PAB.

\section{Pré e Pós testes}

Anualmente uma amostra de alunos do programa é submetida a pré e póstestes, destinados a verificar os ganhos de aprendizagem nos objetivos estabelecidos pelo programa de ensino do projeto. Os resultados apresentados na tabela 4 indicam a média de ganhos de aprendizagem para cada ano do PAB.

O fato de ser ou não alfabetizado, no entanto, reflete níveis significativamente diferentes de desempenho, conforme ilustrado na tabela 5, referentes aos alunos que ingressaram no programa no ano de 2000:

A partir de 1998 a expansão do PAB permitiu identificar que de 20\% a 40\% dos alunos defasados também eram analfabetos, incapazes de decodificar palavras e compreender o seu sentido em frases. A partir daquele ano os alunos defasados analfabetos passaram a ser encaminhados para um programa de alfabetização desenvolvido pelo IAS a partir do método Dom Bosco6.

6. A constatação da existência de analfabetos nas quatro primeiras séries, em escolas e redes de ensino com elevado grau de reprovação e defasagem, revela a existência de práticas pedagógicas duplamente perversas que são adotadas na escola, com a complacência das secretarias de educação. De um lado há reprovação maciça. Essa se aplica sobretudo aos alunos que aprenderam alguma coisa, mas não o suficiente para passar de ano. De outro lado, há a aprovação automática, para alunos que sequer aprenderam a ler. Entre outras, essas práticas revelam que promoção automática, no contexto educacional brasileiro, deve-se muito mais ao descaso com o ensino e com o aluno do que à adoção de práticas eficazes de recuperação do aluno no processo. A mera passagem de tempo não assegura aprendizagem nem significa respeito ao ritmo do aluno. Maiores informações sobre o método Dom Bosco constam dos manuais de operação e manual do professor e podem ser obtidas no Instituto Ayrton Senna (www.senna.com.br). 
QUADRO 3

COMPARAÇÃO ENTRE EGRESSOS MATRICULADOS NA $3^{\text {a }}$ SÉRIE NO ANO 2000 E ALUNOS DO ENSINO REGULAR

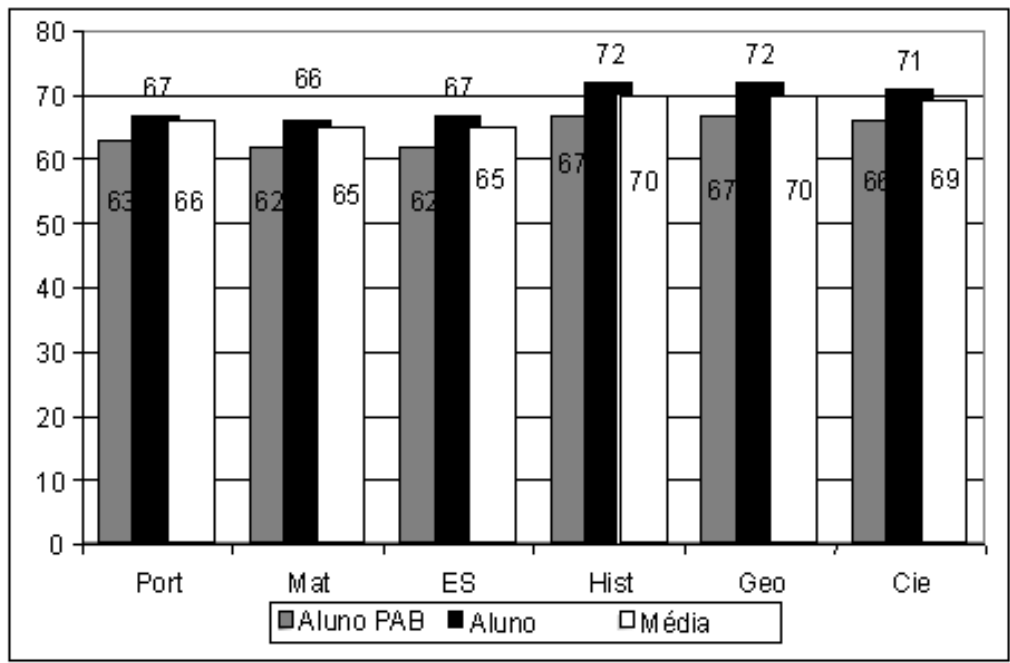

QUADRO 4

COMPARAÇÃO ENTRE EGRESSOS MATRICULADOS NA 4ª SÉRIE NO ANO 2000 E ALUNOS DO ENSINO REGULAR

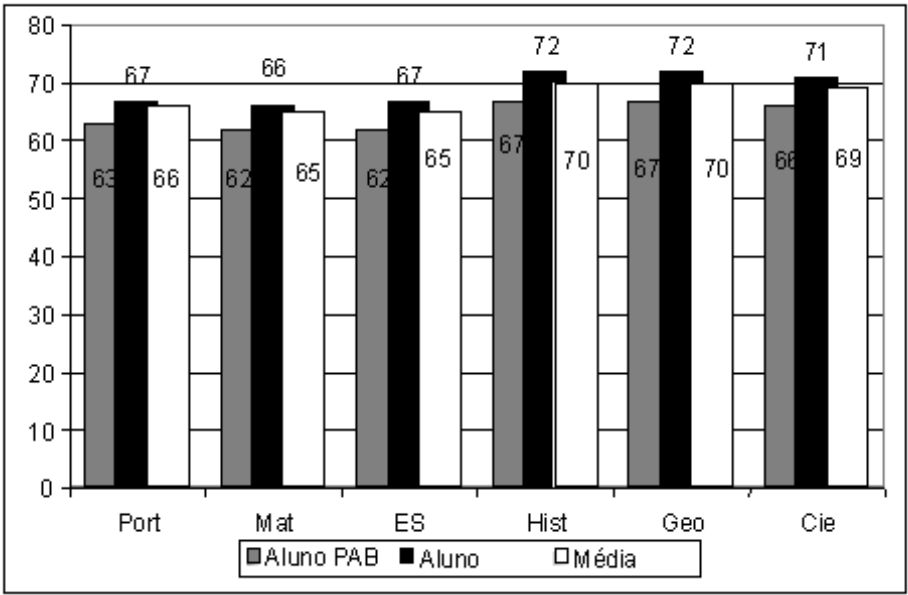

Fonte: FCC, 200 I 
QUADRO 5

COMPARAÇÃO ENTRE EGRESSOS MATRICULADOS NA 5 a SÉRIE NO ANO 2000 E ALUNOS DO ENSINO REGULAR

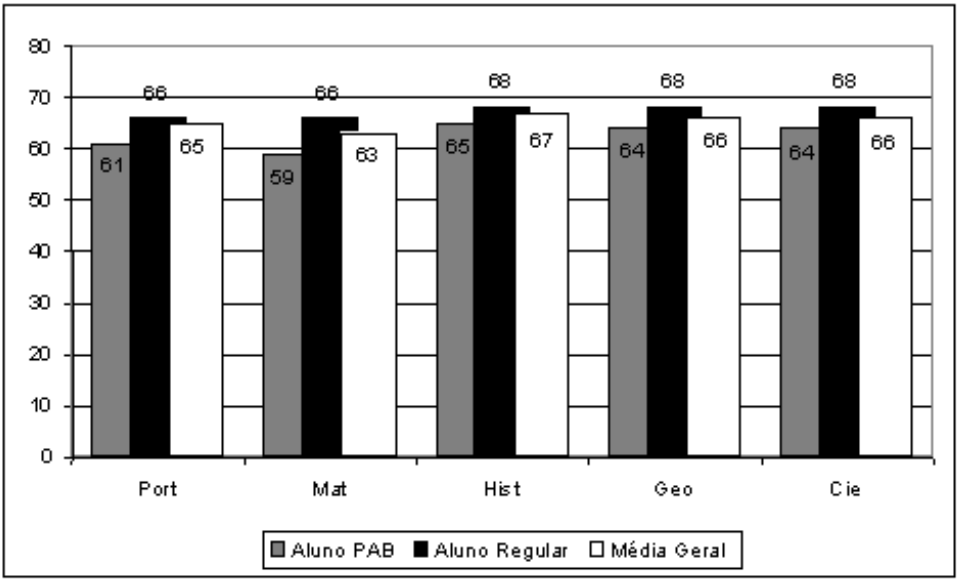

Fonte: FCC, 2001

QUADRO 6

COMPARAÇÃO ENTRE EGRESSOS MATRICULADOS NA 6 a SÉRIE NO ANO 2000 E ALUNOS DO ENSINO REGULAR

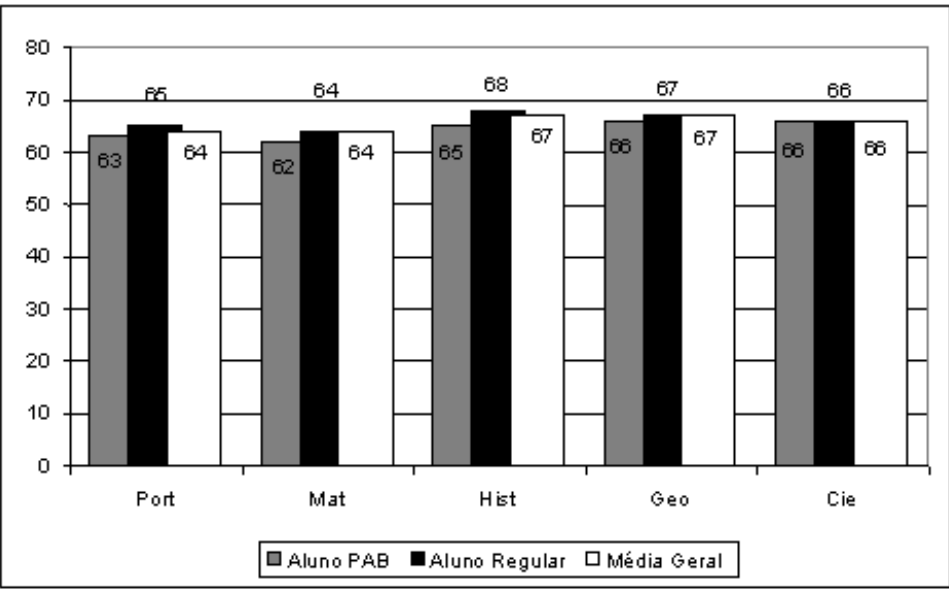

Fonte: FCC, 2001 


\section{QUADRO 7 \\ PORCENTAGENS DE APROVAÇÃO, REPROVAÇÃO, TRANSFERÊNCIA \\ E ABANDONO DOS EGRESSOS DO ACELERA BRASIL \\ EM RELAÇÃO AOS ALUNOS DO ENSINO REGULAR}

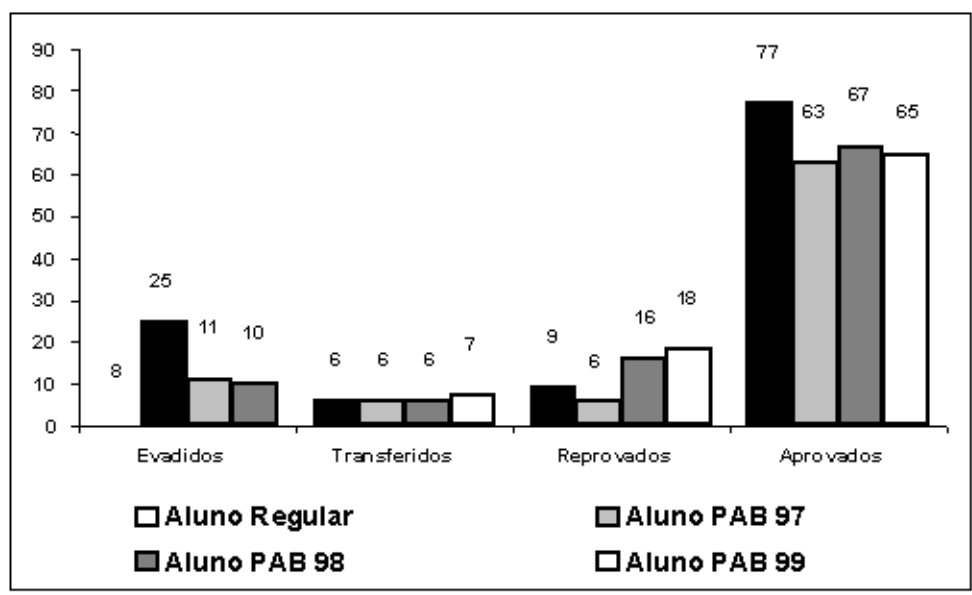

Fonte: FCC, 2001

Os resultados da avaliação elaborada pela Fundação Carlos Chagas, no ano de 200 I , revelam o impacto positivo do programa de alfabetização no aproveitamento de alunos matriculados no programa de aceleração. A coluna "ensino regular", no quadro 6, refere-se a alunos defasados alfabetizados, a coluna "analfabetos" corresponde a alunos que não foram submetidos previamente a um programa de alfabetização. A coluna "Dom Bosco" refere-se a alunos que cursaram o programa durante um semestre anterior à sua entrada nas classes de aceleração. Os resultados do pós-teste mostram que no início do programa os alunos analfabetos e "Dom Bosco" tiveram desempenho semelhante, mas os alunos que cursaram o programa de aceleração depois de alfabetizados por esse método tiveram ganhos de aprendizagem muito superiores a alunos que entraram no programa sem domínio básico de alfabetização (Tabela 6)7.

7. Esses dados sugerem a dificuldade com o uso de testes diagnósticos de alfabetização: os instrumentos de diagnóstico utilizados não discriminaram os $6 \%$ de alunos defasados analfabetos, que não tinham condições de cursar o programa de aceleração. Além disso, os alunos que haviam cursado o Dom Bosco, embora tivessem melhores condições de sucesso, conforme confirmado pelo pós-teste, não se saíram muito melhor do que os alunos analfabetos nos pré-testes. A dificuldade de um diagnóstico correto é um dos fatores que podem explicar os resultados aquém do esperado no Programa Acelera Brasil. 
TABELA 4

PRÉ- E PÓS-TESTES

\begin{tabular}{|l|c|c|c|c|c|c|}
\hline \multirow{2}{*}{ Média } & \multicolumn{3}{|c|}{ Português } & \multicolumn{3}{c|}{ Matemática } \\
\cline { 2 - 7 } Ano & PRÉ & PÓS & Ganho & PRÉ & Pós & Ganho \\
\hline 1997 & & & & & & \\
1998 & 35 & 55 & 20 & 30 & 52 & 22 \\
1999 & $-*$ & 49 & - & $-*$ & 44 & - \\
2000 & 24 & 45 & 21 & 21 & 41 & 20 \\
\hline
\end{tabular}

* No ano de 1998 não foi aplicado o pré-teste.

TABELA 5

DESEMPENHO NO PRÉ-TESTE DE PORTUGUÊS, 2000

\begin{tabular}{lrrrr} 
Ensino Regular & & Método Dom Bosco & Não alfabetizados & \\
\hline 73 & & 21 & 6 \\
\hline
\end{tabular}

Fonte: FCC, 2001.

TABELA 6

GANHOS ABSOLUTOS E RELATIVOS DOS EGRESSOS DO PROGRAMA DE ALFABETIZAÇÃO

\begin{tabular}{cccc} 
& Ensino Regular & Dom Bosco & Analfabetos \\
\hline Pré-teste & 35 & 28 & 26 \\
Pós-teste & 51 & 42 & 33 \\
\hline
\end{tabular}




\section{Comparação com os resultados do Saeb}

Anualmente uma amostra de alunos do programa é submetida a um teste comparável ao do Saeb. A comparação do desempenho dos alunos com a escala Saeb foi feita tomando-se por base a escala correspondente ao período de avaliação do Saeb, divulgado pelo Inep. Desta forma, os alunos do programa em 1997 foram comparados com a escala Saeb de 1995. Em 1998 o desempenho dos alunos foi comparado na escala de 1997 e o desempenho de 1999 e 2000 foi comparado na escala Saeb 95/97. Tendo por objetivo perceber a evolução dos alunos nos quatro anos do programa, em relação à escala Saeb, os valores das diferentes escalas foram transformados em porcentagem pela Fundação Carlos Chagas. Desse forma, as médias do Saeb foram transformadas numa escala em que valem 100 pontos. A partir dessa convenção os alunos do PAB foram comparados com as médias nacionais, usando-se uma mesma escala e testes estatisticamente equivalentes, de acordo com a Fundação Carlos Chagas (Tabelas 7 e 8).

De modo geral, os alunos que apresentaram melhor desempenho em relação à média Saeb Brasil foram os que cursaram o programa nos anos de 1997 e 1998. No ano de 1999 os alunos apresentaram o desempenho mais baixo. Este período corresponde ao ano em que a maioria dos alunos era proveniente das $I^{\mathrm{a}} \mathrm{e}$ $2^{a}$ séries e apresentavam um nível maior de dificuldade em relação ao domínio da leitura e escrita.

TABELA 7

COMPARAÇÃO DAS HABILIDADES MÉDIAS DOS ALUNOS DO PROGRAMA COM A ESCALA SAEB DE LÍNGUA PORTUGUESA, EM PORCENTAGEM

\begin{tabular}{lcccc}
\hline \multicolumn{1}{c}{ Média } & 97 & 98 & 99 & 00 \\
\hline Geral do PAB & 91 & 94 & 77 & 78 \\
Aprovados para a 5 $5^{\mathrm{a}}$ série & 101 & 108 & 88 & 92 \\
Aprovados para $<5^{\mathrm{a}}$ série & 82 & 81 & 60 & 67 \\
SAEB & 100 & 100 & 100 & 100 \\
Ano da escal a SAEB & 95 & 97 & $95 / 97$ & $95 / 97$ \\
\hline
\end{tabular}

Fonte: FCC, 200I. 
TABELA 8

COMPARAÇÃO DAS HABILIDADES MÉDIAS DOS ALUNOS DO PROGRAMA COM A ESCALA SAEB DE MATEMÁTICA, EM PORCENTAGEM

\begin{tabular}{lcccc}
\multicolumn{1}{c}{ Média } & 97 & 98 & 99 & 00 \\
\hline Geral do PAB & 90 & 100 & 88 & 87 \\
Aprovados para a 5 5 série & 100 & 107 & 97 & 101 \\
Aprovados para $<5$ série & 83 & 93 & 76 & 76 \\
SAEB & 100 & 100 & 100 & 100 \\
Ano da escal a SAEB & 95 & 97 & $95 / 97$ & $95 / 97$ \\
\hline
\end{tabular}

Fonte: FCC, 2001.

Outra comparação pode ser estabelecida entre o nível de $4^{a}$ série. A escala Saeb de Português, nível $4^{\text {a }}$ série, corresponde a 175, e a de Matemática, a 250 (Tabelas 9 e 10).

TABELA 9

COMPARAÇÃO DAS HABILIDADES MÉDIAS DOS ALUNOS DO PROGRAMA COM O NÍVEL DE $4^{a}$ SÉRIE DA ESCALA SAEB DE LÍNGUA PORTUGUESA, EM PORCENTAGEM

\begin{tabular}{|c|c|c|cc|}
\hline Mno & Geral PAB & $\begin{array}{c}\text { Aprovados } \\
\text { para }<\mathbf{5}^{\mathbf{a}} \text { série }\end{array}$ & $\begin{array}{c}\text { Aprovados } \\
\text { para a 5 } \mathbf{5}^{\mathbf{a}} \text { śrie }\end{array}$ & $\begin{array}{c}\text { Escala SAEB } \\
\text { utilizada em }\end{array}$ \\
\hline 1997 & 91 & 84 & 102 & 95 \\
1998 & 89 & 77 & 102 & 97 \\
1999 & 82 & 63 & 94 & $95 / 97$ \\
2000 & 83 & 71 & 98 & $95 / 97$
\end{tabular}


TABELA 10

COMPARAÇÃO DAS HABILIDADES MÉDIAS DOS ALUNOS DO PROGRAMA COM O NÍVEL DE $4{ }^{a}$ SÉRIE DA ESCALA SAEB DE MATEMÁTICA, EM PORCENTAGEM

\begin{tabular}{|l|c|c|c|c|}
\hline Média & Geral PAB & $\begin{array}{c}\text { Aprovados } \\
\text { para }<5^{a} \text { série }\end{array}$ & $\begin{array}{c}\text { Aprovados } \\
\text { para a 5a série }\end{array}$ & $\begin{array}{c}\text { Escala SAEB } \\
\text { utilizada em }\end{array}$ \\
\hline 1997 & 63 & 77 & 70 & 95 \\
\hline 1998 & 75 & 70 & 80 & 97 \\
\hline 1999 & 68 & 58 & 74 & $95 / 97$ \\
\hline 2000 & 67 & 58 & 77 & $95 / 97$ \\
\hline
\end{tabular}

Fonte: FCC, 2001

Esses resultados permitem afirmar que:

- em língua portuguesa, apesar de os alunos de 1999 e 2000, aprovados para a $5^{a}$ série, estarem mais distantes da média Brasil, eles possuem as habilidade de $4^{a}$ série indicadas pela avaliação do Saeb;

- em Matemática, embora os alunos tenham se aproximado da média Saeb Brasil, eles, como todos os alunos do ensino regular, não dominam as habilidades e conteúdos de $4^{\mathrm{a}}$ série indicados pelas propostas curriculares;

- a diferença apresentada nos anos de 1999 e 2000, em relação aos anos de 1997 e 1998, correspondem principalmente à série de origem e à inclusão de alunos com maior dificuldade em leitura e escrita. Já a melhora dos alunos em 2000, quando comparada com 1999, deve-se a um maior rigor na seleção dos alunos e ao curso de alfabetização.

Esses resultados ${ }^{8}$ são corroborados pela correlação de resultado da avaliação externa e séries para as quais os alunos foram aprovados pelos seus professores no ano 2000, indicada na tabela II:

8. Dados de anos anteriores comprovam a mesma tendência dos professores. Os resultados mostram que os professores discriminam bastante os alunos - há forte correlação entre série de promoção e notas na avaliação externa, embora essas duas informações sejam independentes. Também mostram que muitos alunos poderiam ter sido promovidos para séries mais 


\begin{tabular}{cc} 
Número de Acertos na Prova & Série de Promoção \\
\hline 24 & 1 \\
35 & 2 \\
36 & 3 \\
43 & 4 \\
58 & 5 \\
71 & 6 \\
\hline
\end{tabular}

Fonte: FCC, 2001.

Por sua vez, os resultados das avaliações externas feitas pela Fundação Carlos Chagas (200 I) revelam que a média dos alunos é fortemente relacionada com a série de origem - alunos de séries mais elevadas logram resultados maiores. Esses dados também mostram que os resultados do programa "caem" à medida que aumenta a presença de alunos de menor nível de escolaridade.

Segundo o relatório, os maiores preditores do desempenho dos alunos são, em ordem: série de origem, morar na zona urbana e ter percepção elevada a respeito do próprio desempenho. Das variáveis que dependem do professor, os maiores preditores do desempenho dos alunos são expectativas a respeito dos alunos e consistência no uso das orientações do programa, particularmente referentes ao desenvolvimento de tarefas de metacognição, tarefas que exigem muita interação cognitiva com os alunos e a realização de tarefas em grupo.

avançadas, o que reforça a idéia de que há pressão para reter os alunos. De resto, o professor não recebe os resultados individuais dos alunos na avaliação externa. E, finalmente, mostram que muitos professores têm maior competência para avaliar do que para ensinar os alunos, ou seja, eles percebem que nível de competência corresponde a que série escolar, mas não conseguem ajudar os alunos a lograrem esses níveis de competência, mesmo diante de oportunidades de trabalho relativamente excepcionais. As diferenças de resultados entre alguns municípios que são muito semelhantes, do ponto de vista socioeconômico e cultural, reforçam o fato de que as variáveis locais de implementação se revelam mais importantes do que eventuais deficiências dos alunos ou do programa. 


\section{Custos e custo-efetividade}

Estudos de custo do PAB já foram relatados em outros documentos (Oliveira, 200 I). Os dados da tabela 12 apresentam um balanço geral dos custos totais do programa ao longo de seus quatro anos de existência. Eles se baseiam no atendimento a um total de 51 .340 alunos de aceleração e 6.91 8 alunos de alfabetização. Isso representa um total de 58.258 alunos, cerca de 2.400 turmas e professores, 240 supervisores e 24 coordenadores municipais. As séries concluídas pelos alunos, apresentadas na tabela 2, totalizam 96.27। (51.340 × I,7 +6.918 × I,3). A base do cálculo é explicada a seguir:

TABELA 12

SÍNTESE DOS CUSTOS

Produção do material utilizado no Programa de Aceleração

Custos de assistência técnica

Custos de gerenciamento e supervisão local

Outros custos locais

Total
$300.000,00$

$12.772 .813,00$

$2.880 .000,00$

$960.000,00$

$16.912 .812,00$

- Produção de material. O material utilizado pelo programa foi desenvolvido originalmente com recursos do FNDE/MEC, no valor total de 2,5 milhões de reais. $\bigcirc$ material não foi utilizado unicamente pelo programa. Estimando-se que até o final do ano 2000 mais de 500 mil exemplares do material foram impressos por diversos usuários, o custo por aluno seria de cerca de 5 reais. Como o programa utilizou cerca de 60 mil exemplares, o custo de produção relativo ao programa pode ser estimado em 300 mil reais. Os custos de produção do material de alfabetização foram financiados pelo projeto e foram incluídos nos custos de assistência técnica.

- Assistência técnica. Inclui os seguintes custos:

a) de assistência técnica relacionada ao acompanhamento e controle do projeto pelo Ceteb, ao longo de quatro anos, incluindo viagens do pessoal do Ceteb e dos municípios para visitas de supervisão e reuniões; 
b) da avaliação externa realizada pela Fundação Carlos Chagas;

c) de desenvolvimento do material de alfabetização;

d) de impressão de 60 mil volumes do material, estimados a um custo médio de 20 reais por volume;

e) de divulgação do projeto.

- Gerenciamento e supervisão local. Incluem o pagamento de um supervisor em tempo integral para cada 10 classes - num total de 240 - e 24 gerentes em tempo integral durante quatro anos, o que totaliza 288 pessoas/ ano. Estimando-se um salário médio de 10 mil reais/ano, o custo local pode ser estimado em aproximadamente 2,88 milhões de reais.

- Outros custos locais incluem a reprodução de materiais, transporte, promoção de eventos e outros custos indiretos, estimados na base de 10 mil reais por ano para cada município.

- Não se incluem nesses cálculos os custos do pessoal próprio e da infraestrutura de comunicações e serviços do IAS, envolvido no gerenciamento do projeto. Se incluídos, esses custos poderiam ser estimados em aproximadamente 800 mil reais adicionais ao longo de quatro anos.

Dividindo-se o gasto total de $R \$ 16.9$ | 2.8 13,00 pelo número de alunos que concluiu o programa teríamos os seguintes resultados:

- Custo-aluno: $\mathrm{R} \$$ 16.912.813,00/58.258 alunos $=\mathrm{R} \$ 290,30$ por concluinte/ano.

- Custo por série concluída. A aceleração permite que o aluno conclua mais de uma série, ao final de um ano letivo no programa. Se o mesmo valor for dividido pelo número de séries concluídas, teríamos: $R$ \$ 16.912.813,00/ 96.27I, o que resulta no custo/aluno série concluída de $R \$ 176,00$.

Esses custos - adicionais aos custos regulares de manter e operar a escola e pagar o professor - devem ser comparados com o custo necessário para promover um aluno defasado (equivalente a 96.27 I séries escolares). $O$ custo médio do aluno no sistema regular é de aproximadamente 500 reais, no Brasil. Se presumirmos que em média esse aluno leva o dobro do tempo, no sistema regular, isso significaria 96.27I $\times 2$ anos letivos $\times 500$ reais, ou seja, 96.27I milhões de reais.

No PAB, os custos totais foram de $\mathrm{R} \$ 29.129 .000,00$ (58.258 anos letivos $x$ 
500 reais) acrescidos de $R \$$ I 6.9 | 2.8 | 3,00, o que dá um total de $R \$ 46.04$ I .297,00. Isso significa uma economia superior a 50 milhões de reais para os municípios envolvidos e representa uma taxa de retorno superior a 300\% ( 16 milhões de investimento geraram uma economia superior a 50 milhões de reais) 9 .

A longo prazo, os objetivos de um programa desta natureza devem computar os custos da redução da reprovação, da repetência e as vantagens decorrentes da redução do número de alunos que podem trazer significativa redução nos custos de operação do ensino fundamental.

\section{Efeitos colaterais: melhoria da qualidade docente}

O objetivo central do PAB é proporcionar a correção do fluxo escolar. Isso implica, de um lado, acelerar os alunos defasados. E, de outro, estancar as causas da defasagem. Parte desse segundo objetivo implica melhorar a competência dos professores para ensinar. $\bigcirc$ PAB não é nem se propõe a ser um programa de capacitação de professores. Na prática, no entanto, pode ser visto como um importante instrumento de capacitação em serviço.

Do ponto de vista formal, o PAB envolve o professor, durante um ano letivo, em mais de 250 horas de atividades formais de capacitação, supervisão dirigida e reuniões de trabalho, em que o professor aprende a dialogar produtivamente com seus colegas para resolver problemas concretos da sala de aula. Essa estratégia temse mostrado muito mais eficaz para melhorar as práticas de trabalho do professor do que cursos e capacitações de caráter formal.

No entanto, integra o programa um curso formal de capacitação, denominado Capacitar, desenvolvido sob a coordenação técnica do autor pelo Sistema Pitágoras de Ensino. Esse curso consiste em quatro conjuntos de 12 vídeo-aulas de aproximadamente 30 minutos cada, referentes às quatro disciplinas básicas do ensino

9. Na prática o benefício do investimento de aproximadamente 12 milhões de reais, investidos diretamente pelo IAS, não se esgota nos alunos do Acelera Brasil, uma vez que o IAS, durante esse período, também desenvolveu programas de regularização do fluxo escolar no Estado do Espírito Santo, durante um ano, e no Estado de Goiás, desde 1999. Muitos dos custos de gerenciamento e apoio a esses programas estão incluídos no total de 12 milhões. No que se refere aos custos diretos para um estado ou município que queira iniciar o programa, esses custos normalmente se situam entre 120 e 150 reais por aluno/ano, dependendo da escala do projeto. Esses custos têm sido observados em projetos de larga escala, como o Educar para Vencer, que vem sendo implementado no Estado da Bahia desde o início do ano 2000 (Oliveira, 200I). 
fundamental: Português, Matemática, Ciências e Estudos Sociais (Geografia e História). Diferentemente da maioria dos cursos de capacitação, esse curso mostra um professor dando aula em situações muito parecidas com a da maioria dos professores. As aulas são estruturadas com base nas mesmas concepções pedagógicas do PAB, com ênfase no desenvolvimento de estratégias de metacognição e na participação ativa do aluno no processo de aprendizagem.

A recomendação do PAB é que todos os professores da escola se reúnam para ver esses programas e planejar uma aula semelhante. A estratégia visa possibilitar que os professores envolvidos no PAB - e já familiarizados com essas metodologias - demonstrem aos seus colegas sua competência com o uso de métodos e estratégias mais eficazes de ensino. Uma avaliação do impacto desse programa (ISCR, 1998) revelou que 100\% dos participantes haviam utilizado o que aprenderam no Capacitar nas semanas seguintes na sua sala de aula. As características do PAB como instrumento de capacitação em serviço de professores são analisadas em outros documentos (Oliveira, 1999; Navarro, Verdisco, 2000) ${ }^{10}$.

\section{DISCUSSÃO}

A discussão é dividida em três partes: limitações, lições e implicações do PAB para a formulação de políticas públicas.

\section{Limitações do PAB}

A principal limitação do PAB refere-se ao descompasso entre sua proposta de corrigir o fluxo escolar numa rede de ensino no prazo de quatro anos e os resultados verificados, que ficam aquém desse desiderato. Corrigir o fluxo escolar implicaria não ter alunos com defasagem superior a dois anos nas $4^{\text {as }}$ séries. $\bigcirc$ levantamento efetuado em março de 200 I demonstra que nenhum dos 24 municípios atingiu esse objetivo, embora pelo menos dez dos 24 municípios tenham apresentado índices de defasagem idade/série inferiores a 10\%. Isso deve ser comparado com a média nacional"', que permanece superior a 40\%. Levantamento

10. Para informações sobre o programa Capacitar, consultar alfaeduc@brfree.com.br

I I. O Censo do Inep de 2000 indica um índice de defasagem de 41,7\%. Esses dados merecem discussão, pois o índice deve ser bem maior, já que dos 35,7 milhões de alunos do ensino fundamental, 8,4 já tinham mais de 14 anos (só aí são quase 25\%). Desse total de 35,7 milhões de alunos, quase $65 \%$ concentram-se nas quatro primeiras séries, evidenciando forte defasagem nesse nível de ensino. 
realizado pelo IAS, ao final do ano letivo, nos municípios da Rede Acelera confirma que a idade dos alunos concluintes da $\mathrm{I}^{\mathrm{a}}$ e $4^{\mathrm{a}}$ série é significativamente menor do que a média nacional, o que ratifica a tendência à regularização do fluxo.

Essa limitação poderia estar simplesmente associada a uma provável ambição irrealista da meta, hipótese essa pouco defensável, já que alguns municípios, de tamanhos e situações variadas, conseguiram seus maiores avanços nos dois primeiros anos do projeto, o que demonstra a viabilidade da proposta. Ademais, o prazo de quatro anos, além de bastante grande, corresponde a um mandato político, o que aumenta a viabilidade de concluir-se uma proposta dessa natureza.

Há diversas outras hipóteses mais plausíveis para explicar os resultados alcançados e que podem servir para reavaliar o acerto da proposta inicial e da viabilidade de sua implementação no prazo previsto. A primeira delas é o grau de municipalização que ocorreu durante esse período, frustrando as previsões iniciais. Esse problema, no entanto, poderia ter sido superado se os municípios envolvidos tivessem realizado anualmente o diagnóstico de defasagem e promovido o encaminhamento de novos alunos oriundos da rede estadual para programas de aceleração. Outra hipótese é a descoberta, no processo de implementação do programa, de um número grande de analfabetos defasados, o que aumentou o prazo necessário para regularizar o fluxo. Na prática, o programa precisa de um ano adicional de intervenção para alunos defasados analfabetos. Isso, no entanto, não invalida a viabilidade da meta, apenas sugere a necessidade de melhor planejamento e melhor coordenação entre os programas de alfabetização e de aceleração.

Uma terceira hipótese refere-se à progressiva pulverização dos alunos à medida que o fluxo vai sendo corrigido nas escolas, o que dificulta e torna mais caro e complexo o atendimento a pequenos contingentes de alunos defasados, sobretudo nas zonas rurais. Uma quarta hipótese é a realimentação do sistema pela produção de analfabetos defasados a partir da primeira série ou do primeiro ciclo de dois anos. Essa hipótese, por sua vez, coloca em cheque um dos objetivos do programa, que não apenas se propõe a regularizar o fluxo escolar, mas mantê-lo regularizado. A existência desse problema, detectada em alguns municípios no início do ano 2000, sugere que as recomendações do programa, referentes ao diagnóstico de novos alunos, à adoção de programas eficazes de alfabetização e à criação de incentivos para atrair excelentes professores alfabetizadores e ex-professores do Acelera Brasil, para as séries iniciais, ainda não foram totalmente implementadas ${ }^{12}$. Uma quinta

12. Para assegurar os avanços obtidos nesses municípios, o IAS criou a Rede Acelera, com o objetivo de estimular e apoiar os municípios a darem os próximos passos necessários para 
hipótese relaciona-se com as mudanças demográficas que afetam alguns municípios, aumentando inesperadamente o número de alunos. Esse fato, nem sempre previsível com grande antecedência, exige uma flexibilidade e capacidade de planejamento e atendimento maiores do que as que foram implementadas. Uma sexta hipótese refere-se à idade com que os alunos entraram no programa: alunos que entraram com idade maior do que dez anos e não foram para a $5^{a}$ série ainda continuarão defasados por algum tempo, mesmo tendo passado pelo programa. Mudou-se possivelmente a trajetória escolar do aluno, mas a correção do fluxo dependerá de sua aprovação nas séries que ainda lhe faltam cursar (FCC, 200 I $)^{13}$.

Todas essas hipóteses, que mais seriam explicações e indicações de limitações, constituem meros desafios, e não justificativas ou desculpas para não atingir a meta. Elas apenas reforçam o caráter ambicioso das metas de um programa que se proponha a regularizar o fluxo escolar em quatro anos, sem considerar a impossibilidade de realizá-lo.

A segunda limitação do programa refere-se à sua meta de promover os alunos para a $5^{\text {a }}$ série ou mais, o que tem sido atingido em cerca de $50 \%$ dos casos, e em maior proporção com alunos provenientes de séries mais avançadas. No entanto, alunos de $1^{\mathrm{a}}$ e de $2^{\mathrm{a}}$ série também foram promovidos para a $5^{\mathrm{a}}$ série, o que demonstra que o programa tem o potencial de chegar à meta preestabelecida. Uma dificuldade, já detectada, estava associada à existência de alunos analfabetos, o que foi sanado com a implementação de um programa de alfabetização. A outra reside na tendência de muitos professores em reter os alunos ou mesmo segurá-los em séries anteriores. Essa hipótese merece maior aprofundamento.

Os dados da avaliação externa da Fundação Carlos Chagas apontam para uma forte correlação entre as notas dos alunos no teste eqüivalente ao Saeb e a série para a qual foram promovidos. Ou seja: os professores autorizam mais saltos para os alunos com melhor desempenho. Esses dados também mostram que os

manter o fluxo regularizado e iniciar processos de melhoria qualitativa em suas redes de ensino. Um outro desdobramento, que inclui 10 dos 24 municípios participantes, além de outros 42 municípios em todo o país, consiste na implementação do Programa Escola Campeã, iniciado em janeiro de 200 I e focalizado no fortalecimento da gestão municipal e escolar. Informações adicionais sobre esse programa podem ser obtidas no IAS.

13. Uma análise adicional da FCC demonstrou que uma parcela significativa dos alunos, mesmo se acelerada para a $3^{\mathrm{a}}$ ou $4^{\mathrm{a}}$ série, ainda teria mais de dois anos de defasagem, contribuindo para aumentar a porcentagem de alunos que foram acelerados, mas que não alteraram as estatísticas da defasagem no curto prazo. 
alunos promovidos para a $5^{\mathrm{a}}$ série obtêm médias idênticas à média nacional dos alunos do Saeb de $4^{a}$ série - independentemente da origem urbana ou rural dos alunos, reiterando a consistência da avaliação dos professores na hora de promover os alunos. Esses mesmos dados mostram, ainda, que há uma grande superposição de resultados entre a amostra do Saeb e a do PAB, ou seja, uma grande quantidade de alunos, mesmo quando a média global dos alunos do PAB é inferior à do Saeb, consegue resultados semelhantes à amostra nacional de alunos concluintes da $4^{\mathrm{a}}$ série. Isso significa que, na prática, um número muito maior de alunos do programa poderia ter sido promovido para a $5^{\text {a }}$ série, se fossem adotados critérios objetivos de promoção, e não simplesmente a decisão local dos professores. Na prática, é sabido que os professores sofrem pressão de seus colegas para não adotarem práticas de promoção mais ambiciosas e têm dificuldade de promover seus alunos, sobretudo os que estavam em séries iniciais, apesar de estarem respaldados pelos dados da avaliação externa. Permanece, portanto, o peso da cultura da repetência, da subjetividade e do formalismo na avaliação dos alunos, para efeito de aprovação e reintegração à turma.

Uma terceira limitação do programa está associada aos resultados de desempenho efetivamente obtidos pelos alunos diante das metas do PAB. A ambição era lograr médias semelhantes às do SAEB para a $4^{a}$ série. Na prática, as médias são inferiores, embora situadas dentro do mesmo desvio-padrão. Como explicar que um programa que adota tantos cuidados metodológicos e de implementação não alcance, com um ano intensivo de esforços, colocar todos os alunos defasados num nível comparável aos dos demais alunos que concluem a $4^{a}$ série?

Algumas respostas já foram apresentadas anteriormente: o programa requer que o aluno esteja adequadamente alfabetizado - a entrada de alunos não alfabetizados prejudica a média do programa e, possivelmente, não se constitui na melhor ajuda que se pode dar ao aluno: conforme evidenciado anteriormente, alunos alfabetizados pelo método Dom Bosco logram melhores ganhos no programa de aceleração do que alunos que não foram devidamente alfabetizados. Uma possível explicação seria a inadequação da proposta metodológica do programa aos professores, uma vez que, embora fortemente estruturado, o programa atua num nível de desempenho cognitivo e metacognitivo muito superior ao que é ensinado normalmente nas escolas. $O$ fato de o programa funcionar bem em diversas escolas de diversos municípios sugere que talvez a melhor explicação esteja em deficiências de implementação. Nos locais em que os professores não estão suficientemente motivados, engajados, supervisionados e apoiados, os resultados tendem a ser menos 
satisfatórios do que naqueles em que o programa é implementado de maneira mais completa e cabal. Tratar-se-ia, portanto, essencialmente de deficiências de acompanhamento e gerenciamento, e não de concepção.

A quarta limitação refere-se à disseminação da "Pedagogia do Sucesso" nas escolas e redes de ensino em que o programa foi adotado. Os questionários aplicados pela Fundação Carlos Chagas no estudo já mencionado revelam que mais de 92\% dos professores demonstram e revelam ter mudado suas práticas docentes, suas atitudes em relação aos alunos e em relação à promoção. No entanto, esses mesmos professores - e os dados agregados de repetência - revelam que a cultura da repetência ainda continua a vigorar até mesmo nas escolas em que o programa foi implementado, podendo gerar a recorrência da reprovação, da repetência e da defasagem.

Uma das estratégias recomendadas pelo programa para ampliar a sua repercussão na escola é introduzir práticas de reflexão e ação coletiva dos professores em torno de problemas concretos de aprendizagem dos alunos. No caso, é sugerido o uso do programa Capacitar como instrumento para essa reflexão, cuja estratégia já foi explicada anteriormente.

O envolvimento e a responsabilização dos diretores das escolas pelo êxito dos seus alunos também podem ser fatores importantes. Eles foram incorporados progressivamente ao programa e, a partir do ano 200I, às estratégias da Rede Acelera Brasil. Com isso, as escolas passam a ser mais envolvidas e responsabilizadas em questões relativas ao calendário escolar, freqüência de alunos e professores, acompanhamento do programa de ensino, introdução de instrumentos de diagnóstico de alunos analfabetos e de intervenções que assegurem a alfabetização e adequada distribuição dos alunos em turmas.

Esses instrumentos e mecanismos, no entanto, ainda se encontram em estágio incipiente de implementação. Ademais, a forte conotação ideológica com que são abordadas as questões de alfabetização no Brasil impedem a rápida introdução de métodos eficazes de ensino. Entre a ideologia, sobre o que deve ser e como conduzir a alfabetização, e a realidade de alunos que não aprendem a ler, predomina a ideologia. Um levantamento realizado no ano de 200 I em 52 municípios participantes do Programa Escola Campeã, também liderado pelo IAS, revelou que em sua esmagadora maioria esses municípios - representativos do ensino público brasileiro - não possuem programas de ensino, programas adequados de alfabetização, livros adequados para alfabetizar, professores formados para alfabetizar ou estratégias para assegurar a lotação de professores alfabetizadores nas escolas. Uma 
análise de todos os livros integrantes do Programa Nacional do Livro Didático, recomendados para a la série do ensino fundamental, por outro lado, revela que nenhum desses livros é adequado para o aluno típico de primeira série do ensino fundamental das escolas públicas. Da mesma forma, estratégias emergenciais de capacitação de alfabetizados, promovidas pelo Governo Federal, são fadadas ao mesmo grau de insucesso típico desse modo de intervenção. A evidência completar sobre a falta de uma política adequada de alfabetização, nas redes estaduais e municipais, revela-se no Saeb da $4^{\mathrm{a}}$ e $8^{\mathrm{a}}$ série, em que transparece de maneira inequívoca a incapacidade dos sistemas públicos de ensino para alfabetizar parcela significativa de seus alunos.

Essas quatro limitações não invalidam as metas, propósitos e resultados do Acelera Brasil. Sugerem, no entanto, a necessidade de esforços adicionais para concluir e consolidar os avanços obtidos nesses municípios. Além disso sugerem precaução na análise de programas de aceleração e de outras tentativas de regularizar o fluxo escolar - como a promoção automática -, que não possuem esse mesmo tipo de cuidado. Ou seja: se, com tantos esforços e cuidados, os resultados são limitados em face do almejado e do necessário, como seria possível acreditar que iniciativas que não possuem metodologias, tecnologias e cuidados mínimos poderiam obter resultados mais eficazes? A experiência analisada sugere que somente o cuidadoso gerenciamento e a avaliação externa e independente podem servir de árbitro.

\section{LIÇÕES}

A experiência do PAB em 24 municípios da Federação, desde 1997, e no programa Acelera Goiás, desde 1999, aliada às experiências iniciais no Maranhão, nos anos 1995-97, a experiência-piloto em Minas Gerais, no ano de 1998, e a experiência que vem sendo desenvolvida na Bahia, desde o ano 2000, todas inspiradas no mesmo modelo e consolidadas no Programa Acelera Brasil, sugerem algumas reflexões e lições relacionadas com o problema da repetência, da defasagem, da correção do fluxo escolar e da promoção de uma cultura do sucesso para substituir a cultura da repetência.

Primeira lição: a defasagem escolar é um problema gigantesco, mas superável. No Brasil, há 36,5 milhões de alunos no ensino fundamental, e apenas 26 milhões de crianças de 7- 14 anos. Só aí já temos 10,5 milhões de defasados. Dentro do sistema educacional há outros vários milhões de alunos que carregam mais de dois anos de defasagem idade-série. Os cuidados, dificuldades e resultados de 
um projeto como o PAB sugerem que não existem soluções fáceis, simples ou milagrosas para resolver o problema. Levar um aluno defasado ao nível de $4^{\mathrm{a}}$ série demanda um esforço considerável do aluno e do sistema de ensino. Esperar que a mera passagem do tempo, através de regras de promoção automática, irá levar o aluno ao domínio das competências esperadas é não compreender o conceito de ritmo de aprendizagem, é acreditar na pedagogia do milagre. Por outro lado, apenas batizar qualquer iniciativa de "aceleração de aprendizagem" - prática rapidamente difundida em diversos estados e municípios - não significa nada, a não ser a trivialização de um rótulo. É possivelmente por essa razão que projetos que apenas se denominam "aceleração de aprendizagem" não logram resultados positivos, nem do ponto de vista de regularizar o fluxo escolar - que nem é sua proposta - nem do ponto de vista de melhorar o desempenho dos alunos. Essa também pode ser a explicação para o fato de que nenhum desses projetos publica evidências a respeito do desempenho de seus alunos. Trata-se de uma área difícil, espinhosa, em que os resultados positivos não vêm com facilidade.

Uma das possíveis explicações para os êxitos logrados pelo Programa Acelera Brasil residiria no ajuste entre sua estratégia pedagógica, sua tecnologia de intervenção e seus instrumentos de acompanhamento, controle e avaliação. A estratégia e os materiais pedagógicos são focalizados diretamente no aluno para superar eventuais carências e deficiências do professor. A tecnologia de intervenção estrutura as ações de alunos e professores de forma a maximizar os procedimentos metacognitivos e o domínio das competências pelos alunos. $\bigcirc$ professor recebe apoio permanente, a capacitação é feita durante o processo, sobre problemas concretos, e não sobre cursos abstratos ou acadêmicos. Os instrumentos de acompanhamento, controle e avaliação permitem monitorar e assegurar o ritmo do programa e corrigir eventuais desvios e dificuldades dos professores. Eles também permitem calibrar as decisões dos professores referentes à promoção dos alunos, assegurando-lhes apoio e mantendo uma imagem de seriedade e compromisso com resultados. Esses instrumentos permitem que o programa opere com professores típicos das redes públicas, bastando seu compromisso e vontade de acertar. Os materiais centrados no aluno propiciam também que os mesmos professores, que antes não ensinavam, e os alunos, que antes não aprendiam, tenham sucesso já nas primeiras aulas. Esse sucesso é assegurado por uma característica do material: o aluno realiza pequenos projetos num curto espaço de tempo - no máximo um ou dois dias - e comprova que é capaz de dar certo na escola, fato que é novo na experiência do aluno multirrepetente. No conjunto, a estrutura gerencial permite expandir o pro- 
grama sem perda de qualidade, fenômeno raro em projetos educacionais: o programa inicialmente previsto para 14 municípios estendeu-se para 24; com o mesmo rigor e mesmos resultados, foi aplicado no Estado de Goiás a milhares de alunos e, seguindo o mesmo modelo, implementado simultaneamente em 45 municípios da Bahia, atingindo mais de 20 mil alunos no primeiro ano, mais de 200 mil no segundo ano, com resultados eqüivalentes aos do $\mathrm{PAB}$, conforme documentado por resultados de avaliação externa (Oliveira, 200 la). Trata-se, portanto, de uma estratégia de inovação que se comprovou adequada, robusta e capaz de se sustentar sem perda de qualidade no processo de disseminação.

A estratégia de implementar o programa em municípios - a única possível em seu início - demonstrou suas vantagens e limitações. Por um lado, é coerente com a Constituição Federal e as leis educacionais que estabelecem o município como responsável pelo ensino fundamental. Por outro lado, como na prática a municipalização ainda não se tornou uma política pública consistente, a existência de duas redes e a transferência de alunos entre elas podem frustrar os melhores esforços de uma rede municipal para corrigir o fluxo escolar. Daí a importância de estratégias que articulem, pelo menos em cada município, o esforço conjunto e simultâneo das duas redes - como vem sendo feito no caso de estados como Bahia e Goiás. A fragmentação de redes e a indefinição de responsabilidades que decorrem do "regime de colaboração", previsto na Constituição Federal, tornam impossível, na prática, a responsabilização das autoridades - o que dificulta um ataque mais eficiente ao problema do fluxo escolar.

Segunda lição: a correção definitiva do fluxo escolar exige um esforço duplo no campo da alfabetização. Por um lado, exige programas vigorosos e eficazes para diagnosticar e alfabetizar os defasados analfabetos. Um exemplo é o do método Dom Bosco de alfabetização, que demonstrou capacidade de operar com sucesso em escala. Isso é prova cabal de que é possível alfabetizar alunos - mesmo os mais "atrasados" - desde que se utilizem métodos, materiais e maneiras adequados. É prova também de que escolhas apropriadas podem operar com razoável grau de sucesso, inclusive com professores que nunca tiveram uma formação à altura. Essa experiência sugere que capacitar tais professores pode ser um equívoco, sobretudo quando a capacitação insiste na adoção de métodos e estratégias que não se coadunam com as competências do professor e suas condições de trabalho. A curto prazo, soluções que buscam adequar características de alunos, professores e condições de trabalho, através de métodos robustos e estruturados, podem ser muito mais eficazes. 
O outro esforço refere-se à necessidade de implementar programas regulares de alfabetização para os novos alunos que ingressam com a idade correta. Os dados do PAB mostram que mesmo em municípios em que explicitamente se procurou assegurar esse objetivo, isso ainda não começou a ocorrer: o número total de alunos represados nas primeiras séries ainda é muito grande, e o número de analfabetos defasados continua a crescer, embora em proporções menores. Isso não se resolve com soluções emergenciais - sejam programas de aceleração ou programas de capacitação de professores. A longo prazo, a única solução definitiva consiste na formação de professores alfabetizadores nas escolas normais e escolas de formação de professores antes de sua entrada no sistema educacional. Uma boa formação é incompatível com uma formação unilateral e sectária, baseada na disseminação de modismos e palavras de ordem, que insiste em desconhecer os progressos da psicologia cognitiva e das pesquisas relacionadas com alfabetização, realizados nas últimas décadas em diferentes países do mundo, e rejeita qualquer possibilidade de pluralismo, confronto de idéias e confronto com dados empíricos. A história talvez venha demonstrar como a leviana adesão acrítica do establishment pedagógico a pressupostos mal-assimilados, mal-digeridos e propagados como "construtivistas" terá contribuído para atrasar a correção de rumos nas políticas de alfabetização no Brasil. Os esforços dos governantes, particularmente desde 1995, em desqualificar e desmoralizar as escolas normais, em vez de aprimorá-las, e a comprovada inadequação dos cursos de Pedagogia para formar professores alfabetizadores asseguram que o país continuará despreparado para lidar com a alfabetização inicial dos alunos nas escolas. Sem a adoção de vigorosos programas regulares de formação de professores alfabetizadores e incentivos para sua permanência nas primeiras séries, a defasagem será realimentada, e serão frustrados os esforços de programas voltados para regularizar o fluxo escolar (Oliveira, no prelo).

Até que esses problemas sejam equacionados - o que é um projeto ambicioso e de médio prazo - as redes de ensino enfrentarão problemas na definição de programas de alfabetização e escolha de professores. Da mesma forma as escolas terão dificuldades na escolha de métodos e materiais didáticos, tendo em vista não apenas a limitação da oferta, mas sobretudo a sua inadequação às situações típicas do alunado das escolas públicas, que provém de lares praticamente iletrados. A existência de alternativas que mostraram alguma eficácia, como o método Dom Bosco, poderá lograr bons resultados naquelas culturas escolares em que assegurar a aprendizagem do aluno for considerada tarefa mais importante do que simplesmente reverberar palavras ocas de doutrinas pedagógicas desprovidas de qualquer rigor conceitual e eficácia prática. 
A terceira lição provém das informações obtidas a partir das análises hierárquicas que associam características dos professores com desempenho dos alunos, constantes do relatório da Fundação Carlos Chagas (1991). Empiricamente isso quer dizer que o programa é tão mais bem-sucedido quanto mais cuidadosamente é implementado na sala de aula. No caso do PAB, isso sugere que a pedagogia embutida na tecnologia educacional do programa foi adequadamente concebida e produz resultados. Para que ela surta efeito em todas as salas de aula, no entanto, é necessário redobrar os cuidados na supervisão do programa, a fim de assegurar que todos os professores desempenhem adequadamente o seu papel. Este é um ponto central em qualquer processo estruturado de ensino - e mais importante nos casos em que a formação deficiente e limitada dos professores requer uma forte aderência entre a prática dos professores e as metodologias preconizadas, para que os efeitos cognitivos do programa sejam alcançados. Ou seja: não basta ter uma estratégia bem estruturada, é preciso assegurar que ela seja implementada adequadamente em cada sala de aula.

\section{Implicações para a formulação de políticas públicas}

O objetivo maior do IAS, ao patrocinar o PAB, foi o de demonstrar ao país que existem estratégias viáveis, que podem ser implementadas em escala e a custos razoáveis, para resolver o problema número um da educação brasileira: a correção do fluxo escolar. Em que medida o instituto pode considerar alcançado o seu objetivo?

O tema da regularização do fluxo escolar é de recente extração. Embora a pedagogia da repetência venha sendo denunciada há décadas - e com mais ênfase a partir dos estudos de Sérgio Costa Ribeiro, no início dos anos 80 - somente por volta de 1994 começam as primeiras propostas de elevar o problema do nível pedagógico para o nível de estratégias e políticas públicas. Isso ocorreu de forma simultânea e independente nas propostas de governo de Roseana Sarney, no Maranhão, e de Mário Covas, em São Paulo. No plano federal o conceito foi incorporado formalmente no plano político-estratégico do Ministério da Educação e Cultura - MEC ( 1995) - como uma prioridade. O primeiro passo concreto consistiu no apoio financeiro à produção do material que posteriormente serviu de base aos programas PAB e assemelhados, e que ficou conhecido como o "material do Ceteb"|4.

14. O material desenvolvido inicialmente pelo Ceteb contou com recursos do Ministério da Educação e Cultura intermediados com o apoio da Fundação para o Desenvolvimento da 
A partir do ano de 1997, o MEC colocou à disposição de Secretarias de Educação materiais dos programas do Ceteb e do programa desenvolvido pelo governo estadual de São Paulo, e ao mesmo tempo anunciou apoio financeiro para programas de aceleração. Posteriormente o Estado do Paraná desenvolveu o projeto Ensinar e Aprender para as séries $5^{\mathrm{a}}$ a $8^{\mathrm{a}}$. A Fundação Roberto Marinho passou a promover a utilização dos materiais do Telecurso em programas denominados "aceleração". Diversas outras iniciativas de estados e municípios, com maior ou menor grau de estruturação, seriedade e compromisso com resultados passaram a ser desenvolvidas com o nome de "aceleração da aprendizagem". Os indicadores do Censo de 1999 apontavam para mais de I,2 milhão de alunos matriculados em programas de aceleração ${ }^{15}$.

Os avanços são claros. O tema foi reconhecido, entrou na pauta oficial, virou dado do censo e instrumento balizador de políticas. Alguns recursos do governo federal - e recursos vultosos de alguns estados como São Paulo, Paraná, Goiás, Bahia, Espírito Santo -, além dos do Instituto Ayrton Senna, foram investidos.

Seria inadequado atribuir ao PAB a introdução dessas políticas. Mas talvez não seja inadequado derivar desse programa três contribuições importantes para a formulação de políticas adequadas de aceleração de aprendizagem e de correção do fluxo escolar.

Primeiro, a experiência do PAB ajuda a colocar o problema da aprendizagem, da repetência e da defasagem em seus devidos termos: trata-se, antes de

Educação - FDE - da Secretaria de Educação do Estado de São Paulo. A elaboração do material foi feita sob a orientação e responsabilidade técnica do autor deste artigo, e contou com profissionais ligados ao Centro dos Professores do Estado de Minas Gerais - CEPEMG. Posteriormente o material foi revisto pela equipe técnica do Ceteb em razão dos resultados da implementação, e complementado com outros instrumentos pedagógicos e gerenciais. Informações sobre a versão atualizada pelo IAS podem ser fornecidas por este instituto. $O$ que era inicialmente apenas um material para os alunos foi convertido pelo Programa Acelera Brasil num conjunto estruturado de manuais, informações e instrumentos pedagógicos e gerenciais. $\bigcirc$ material original para os alunos, produzido pelo Ceteb, ainda continua disponibilizado pelo MEC, embora em muitas redes de ensino o desfigurem e o utilizem até mesmo sem mencionar os nomes de seus autores.

15. O problema com a denominação "programas de aceleração" é que muitos estados e municípios apenas batizaram cursos supletivos ou cursos regulares de programas de aceleração muitas vezes motivados pela possibilidade de obter recursos do Fundef ou mesmo pelos recursos prometidos pelo MEC para programas desse tipo. $\bigcirc$ próprio valor oferecido pelo MEC, de menos de 20 reais por aluno, sugere que se trata, em geral, de intervenções pouco cuidadosas, de caráter muito superficial. $\bigcirc$ fato de que nenhum desses programas possui avaliação externa também é sintomático de seu grau de compromisso com resultados. 
tudo, de um problema de política educacional, e não apenas de mera inovação pedagógica ou de algo que possa ser superado com intervenções baratas, ligeiras ou superficiais. Daí a necessidade de que programas dessa natureza apresentem evidências sobre seus resultados e impacto na aprendizagem do aluno e na correção do fluxo escolar - sob o risco de confundir o público e misturar intervenções eficazes com intervenções ineficazes ou meramente ritualistas ou formais.

No que se refere à correção do fluxo escolar, a experiência do IAS é igualmente ambiciosa, mas os resultados obtidos até o momento não permitem conclusões definitivas.

$\mathrm{Na}$ ótica adotada pelo PAB, torna-se claro que programas eficazes para corrigir o fluxo escolar requerem alguns ingredientes que devem estar todos presentes, ao mesmo tempo e durante um bom período de tempo: forte vontade política, compromisso para tratar de um programa por um prazo mínimo de quatro anos, tecnologia adequada de sala de aula e supervisão, recursos adequados a tempo e a hora, um forte componente gerencial, além de avaliação externa. Exigem, também, para uma solução definitiva, a articulação entre redes estadual e municipal e a adoção de novas práticas dentro das escolas - sobretudo práticas de diagnóstico de novos alunos, alfabetização de alunos defasados e políticas eficazes de alfabetização de novos alunos. Isso equivale a uma verdadeira estratégia de guerra - em que algumas batalhas vencidas não implicam necessariamente a derrocada do inimigo.

Ao mesmo tempo, a experiência do PAB com a aceleração de aprendizagem e correção de fluxo coloca em questão as alternativas ditas de "aceleração de aprendizagem", que vêm sendo desenvolvidas em diversos pontos do país. Primeiro, a falta de avaliação externa e de publicação de resultados de outros programas de aceleração de aprendizagem impede conclusões a respeito de estratégias e custos alternativos. Além disso, sugere que esses programas possam estar tendo problemas ainda maiores do que teve o PAB, pois mesmo aqueles que foram avaliados não divulgaram seus dados para escrutínio público. Ou seja, o simples fato de batizar um programa com o nome de "aceleração de aprendizagem" não significa nada.

Além disso, a análise do impacto de programas de aceleração através de dados agregados, como os do Saeb, precisa ser cercada de muitos cuidados, tanto para caracterizar adequadamente as amostras quanto os tratamentos. No caso do PAB, por exemplo, seus alunos não são captados na avaliação do Saeb, pois integram um programa especial não seriado. Além disso, seus melhores alunos saltam diretamente para a $5^{a}$ série. Portanto, afirmações gerais a respeito do impacto absoluto ou relativo de programas de aceleração de aprendizagem devem ser anuncia- 
das e analisadas sem o sensacionalismo da mídia e com a prudência que o assunto requer. Instituições governamentais, como o Inep, poderiam colaborar com o aprofundamento da questão, coletando e divulgando dados com os devidos cuidados. As informações divulgadas por esse órgão sobre esse tema, até o momento, servem mais para confundir do que para esclarecer onde estão os problemas e onde estão as soluções.

Em síntese: o PAB, apesar de seus modestos resultados, está oferecendo à comunidade educacional uma estratégia de intervenção calcada na evidência empírica a respeito de seus ganhos. Esse parece ser um caminho mais adequado para a superação dos problemas educacionais e para a discussão de políticas públicas do que a mera discussão ideológica a respeito de preferências teóricas ou metodológicas, desprovidas de rigorosas evidências a respeito de seu impacto.

Segundo, os êxitos e limitações de programas como o Acelera Brasil sugerem a necessidade de examinar as outras opções para corrigir o fluxo escolar. Examinemos pelo menos três dessas opções.

Uma delas consistiria em simplesmente redistribuir os alunos nas turmas, colocando cada um na sua faixa etária correspondente. Feita uma vez na vida, essa estratégia poderia até mesmo corrigir o fluxo escolar, ainda que com o sacrifício de uma legião de alunos, mas essa decisão precisaria ser acompanhada de outras medidas para manter o fluxo corrigido. A medida nunca chegou a ser explicitamente advogada, teria dificuldades políticas e práticas, e dificilmente resolveria o problema a longo prazo.

Uma outra consiste na adoção de práticas de ciclos, com promoção automática dentro dos ciclos. Os resultados das primeiras tentativas de ciclos escolares foram analisados por Sérgio Costa Ribeiro, que detectou a persistência da pedagogia da repetência no final do ciclo. Nos últimos anos, e mais recentemente nos primeiros meses do ano 200 I, o Ministério da Educação e da Cultura começou a divulgar informações a respeito da possível eficácia de ciclos e de promoção automática. A falta de divulgação de evidências empíricas a respeito não permite qualquer análise dessas informações ${ }^{16}$.

16. Embora o discurso oficial do governo federal insinue dispor de informações a esse respeito, não existe, no Brasil, publicação que forneça evidências a respeito dos possíveis benefícios da política de ciclos ou de promoção automática. Isso não significa que essas estratégias não possam ter resultados positivos, apenas que as evidências não foram apresentadas. 
A existência de analfabetos defasados, por sua vez, denuncia a precariedade dos mecanismos tanto de reprovação em massa quanto de promoção automática, bem como joga por terra o pressuposto de que basta dar tempo ao aluno que ele acaba aprendendo. Promoção automática, no caso dos alunos defasados, significa simplesmente deixá-los numa série posterior, sem alfabetizá-los, conforme demonstrado empiricamente pelos resultados apresentados nesse trabalho e no decorrer do projeto nele analisado. A mera passagem de tempo não permite aos alunos se alfabetizarem. E não existem instrumentos e mecanismos, nem mesmo em municípios que já despertaram minimamente para problemas de qualidade de ensino, que permitam a um professor de $2^{\mathrm{a}}$, $3^{\mathrm{a}}$, ou $4^{\mathrm{a}}$ série cuidar de alunos analfabetos. Portanto, os dados empíricos aqui apresentados contrapõem-se frontalmente às propostas que afirmam que o mero passar do tempo daria ao aluno condições de prontidão, maturidade ou outras que lhe permitissem se alfabetizar. Portanto, a discussão da repetência versus promoção automática merece um aprofundamento maior do que o sectarismo entre dois extremos. Se a mera repetência não ajuda, ou mesmo atrapalha, a mera promoção automática tem igual, senão pior, efeito. Portanto, são necessárias outras saídas, como programas de aceleração, programas de recuperação e estratégias alternativas para enturmar os alunos.

Para que as escolas saibam o que se espera delas, parece ser de bom alvitre que as redes de ensino possuam programas de ensino e velem para que sejam efetivamente implementados nas salas de aula. Meras preocupações estatísticas e com melhoria de índices poderão contribuir para agravar ainda mais uma situação que já é caótica. Um levantamento efetuado pelo IAS em 52 municípios, em 27 estados do Brasil, participantes de um programa de gestão educacional, no primeiro semestre de 200I, revelou que praticamente não existem programas de ensino nem nas secretarias nem nas escolas. Ora, a inexistência de programas sugere também a inexistência de clareza sobre resultados e responsabilização das escolas. Esse fato, aliado a um ciclo ainda maior de tempo para a escola produzir resultados sugere que políticas de ampliar ciclos e promover os alunos de forma automática, sem cuidados especiais, podem produzir resultados ainda mais negativos, tendência sinalizada pelos resultados do Saeb de 1999.

Estratégias como as que vêm sendo adotadas pela Secretaria Estadual de Educação de São Paulo, sob o nome de "progressão continuada", são promissoras. Diferentemente do que ocorre no resto do país, essa estratégia, além de articulada de forma orgânica, está acoplada a rigorosos mecanismos de avaliação externa, o que poderá permitir a correção dos rumos no processo (Reali, $200 \mathrm{I}$ ). 
Finalmente, há intervenções de natureza legal que poderiam contribuir para encaminhar uma solução para o problema da correção do fluxo escolar. No contexto presente, a mais eficaz poderia consistir no aprimoramento do Fundef. Tal como se apresenta hoje, o Fundef vem motivando inúmeros estados e municípios a diluir os recursos que seriam destinados ao ensino fundamental, seja através de programas "fantasma" de aceleração, seja ampliando o acesso do ensino fundamental a crianças com 6 anos ou menos de idade. Fiel à sua intenção original, limitar o Fundef aos alunos de 7 a 14 anos poderia induzir os municípios a traçar estratégias eficazes para corrigir o fluxo escolar. Essa medida poderia ser ainda mais eficaz se associada a apoio financeiro para a correção do fluxo escolar e com estímulos para a municipalização do ensino, já que as redes estaduais de ensino são praticamente redundantes - na maioria dos estados o tamanho da rede estadual eqüivale ao grupo de alunos com mais de 14 anos. $O$ Censo do IBGE revela a existência de 26.5 milhões de crianças de 7 a 14 anos no país. As redes municipais e particular oferecem, juntas, 20 milhões de vagas. Portanto, das 17 milhões de vagas oferecidas pelas redes estaduais, menos de 7 milhões seriam necessárias para a cobertura completa de alunos em idade regular.

Um esforço articulado de corrigir o fluxo escolar e ao mesmo tempo municipalizar o ensino poderia ser um primeiro e importante passo para a melhoria da qualidade da educação fundamental. Esse passo, no entanto, depende de um amadurecimento cultural e político que ainda não se mostra visível no horizonte, em que predominam os interesses políticos e de exercício de poder. Os estudos de custo do PAB e de programas similares, como o programa de regularização do fluxo escolar do Estado da Bahia (Oliveira, 200 I), revelam que os investimentos necessários para promover essa mudança seriam menores do que o custo anual do desperdício que hoje o país paga para manter as ineficiências que caracterizam as redes estaduais e municipais de ensino.

\section{REFERÊNCIAS BIBLIOGRÁFICAS}

BRASIL. Ministério da Educação e Cultura. Plano político-estratégico 1995-1998. Brasília, 1995.

FUNDAÇÃO CARLOS CHAGAS. Programa Acelera Brasil: avaliação final Municípios. São Paulo: FCC/DPE, 2001. 
INSTITUTO AYRTON SENNA. Acelera Brasil: passo a passo. São Paulo, 2001 .

ISCR. Avaliação do programa Capacitar. Belo Horizonte: Instituto Internacional de Avaliação Sérgio Costa Ribeiro, 1998.

NAVARRO, J.C.; VERDISCO, A. Teacher training in Latin America: innovations and trends. Washington, D.C.: Banco Interamericano de Desenvolvimento, Technical Papers Series, 2000.

OLIVEIRA, J.B.A. Alfabetização e construtivismo: um casamento que não deu certo. Ensaio. (no prelo)

. Custos e benefícios de um programa para regularizar o fluxo escolar no ensino fundamental: novas evidências. Ensaio, v. 32, n.9, p. 305-343, jul./set. 200 I.

. Learn as you teach: the accelerated learning program in Brazil and its approach to teacher education. Costa Rica, 1999. [Artigo apresentado na Conferência Teacher Training in Latin America: innovations and trends.]

- A Pedagogia do sucesso. 5. ed. São Paulo: Saraiva, 200 la.

OLIVEIRA, J.B.A.; CHADWICK, C. Aprender e ensinar. São Paulo: Global, 200 I.

REALI, A. M. M. R. Indicadores educacionais, professores e a construção do sucesso escolar. Ensaio, v. 30, n. 9, p. 79-108, jan./mar. 2001. 
